\section{University of New Hampshire}

Carsey School of Public Policy

\section{CARSEY RESEARCH}

National Issue Brief \#88

Summer 2015

\title{
Behind at the Starting Line Poverty Among Hispanic Infants
}

\author{
Daniel T. Lichter, Scott R. Sanders, and Kenneth M. Johnson
}

$\mathrm{H}$ ispanics are driving U.S. population growth. Representing just 16 percent of the U.S. population in 2010, Hispanics accounted for the majority of U.S. population growth over the past decade. The current emphasis on immigration in public discourse and policy reflects the commonplace assumption that Hispanic population growth is driven largely by new immigration. Yet, most Hispanic growth today is due to Hispanic births, not immigration. ${ }^{1}$ Fertility represents a large second-order effect of past and current immigration. The often unappreciated impact of U.S.-born Hispanic infants on population growth raises an important policy question: Do Hispanic infants start life's race behind the starting line, poor and disadvantaged?

Here we examine the economic circumstances of Hispanics, placing the emphasis squarely on infants. We ask: Do Hispanic infants start life's race behind the starting line, poor and disadvantaged?

The question of whether Hispanic infants start life at an economic disadvantage has broad policy implications. Poverty at birth threatens childhood development trajectories, later academic achievement, transitions to productive adult roles, and, ultimately, incorporation into the economic, social, and political mainstream. ${ }^{2}$ Nor is this just a highly localized concern in a few traditional Hispanic settlement areas, because Hispanics are now widely distributed geographically. America’s Hispanic population has dispersed from established gateways in the Southwest and a few large urban cores to new destinations throughout the Southeast, the Pacific Northwest, and the agricultural heartland. ${ }^{3}$ Most Hispanics continue to reside in metropolitan areas, where they accounted

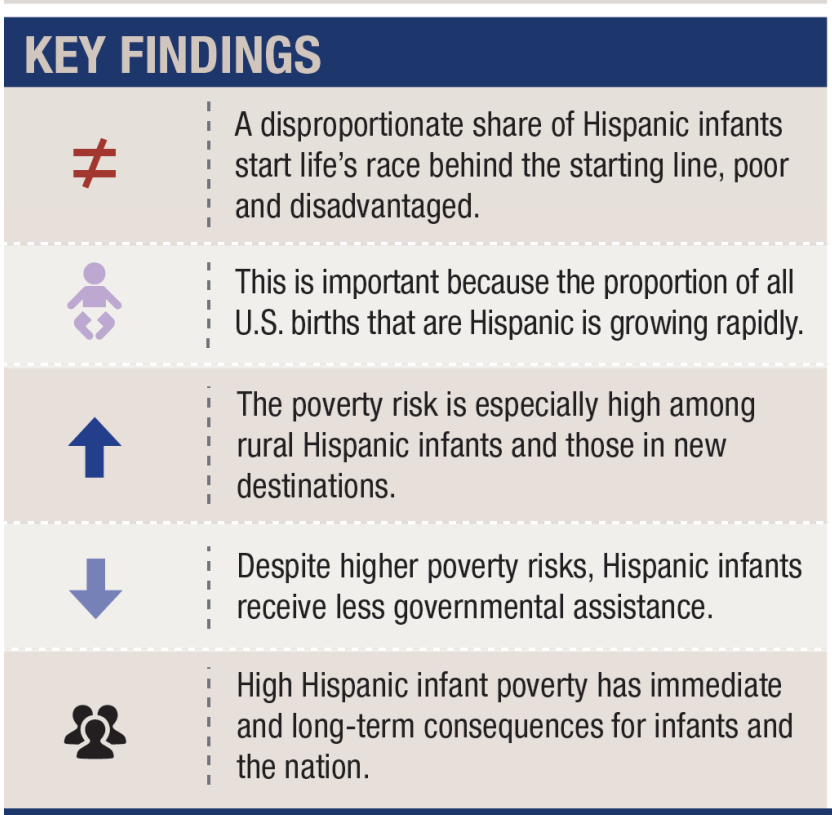

for nearly 55 percent of recent population gains. Yet, Hispanic growth has had even greater impacts in rural America. A burgeoning Hispanic population accounted for two-thirds of the rural population gain, though Hispanics represented less than 7 percent of the population in 2010. In many rural areas, Hispanics provide a demographic lifeline to dying small towns.

Births account for a growing share of the Hispanic population increase: nearly 25 percent of all U.S. births are now to Hispanics. Our focus here is on the question of how many Hispanic infants begin their lives in poverty. In our previous research, we demonstrated that the growing proportion of U.S. births that are Hispanic is causing America to become more diverse from youngest to oldest. ${ }^{4}$ Diversity as well as economic incorporation are occurring from the "bottom up"-beginning with infants and children. Here we examine the comparative economic circumstances of Hispanics but, unlike previous studies, 
we place the emphasis squarely on infants. The period in utero and during early infancy is especially critical for brain development and later cognitive, emotional, and physical outcomes. Poor infants also face clear developmental disadvantages that persist into adulthood. ${ }^{5}$ In the absence of upward socioeconomic mobility, childhood poverty contributes to poverty in adulthood, a statistical fact that will take on special significance if intergenerational mobility declines and inequality grows. ${ }^{6}$

\section{Fertility, Geography, and Poverty}

The conventional view is that economic, cultural, and political incorporation that occurs in established immigrant gateways or enclaves provides a platform for immigrant geographic mobility-to neighborhoods with better housing, situated in middle-class communities with more opportunities for children. Today, however, the unprecedented geographic spread of the historically disadvantaged Hispanic populations from established gateway states to new destination states (Figure 1) suggests the possibility of a new ghettoization of immigrant groups, which is reinforced rather than reduced by inmigration and high fertility in new destinations.

Among immigrant populations, low and declining fertility is sometimes regarded as a proxy indicator of economic incorporation and assimilation. Low fertility both reflects and reinforces upward social mobility, which is revealed in the short-term and long-term economic trajectories of children. ${ }^{7}$ Conversely, current patterns of Hispanic fertility have placed upward demographic pressure on poverty rates in those communities and regions where Hispanic workers and their families have relocated. Growing poverty among infants presumably reflects the fact that:

- Childbearing among Hispanics is higher on average than among non-Hispanics. Among Hispanics, there were 80.2 births per 1,000 women of reproductive age compared to a rate of 64.1 for the United States overall and 58.7 for non-Hispanic whites. The implication is clear: high Hispanic fertility is contributing to America's new diversity. ${ }^{8}$

- Poverty rates are higher among the Hispanic population than among many other groups. Today, over 5.4 million U.S. Latino children live in poverty, a number that exceeds the number of poor white children and the number for every other racial or ethnic minority group. Latino children comprise 23.1 percent of America's children but 37.3 percent of its poor children.
Poverty rates are high for Hispanics generally at 26.6 percent in 2010, but they are especially high (34.9 percent) among Hispanic children. ${ }^{9}$

\section{- Hispanic childbearing is highest among the} poorest, least educated, and more disadvantaged (for example, noncitizens or non-English speak-

ers). Less-educated and poor mothers contribute disproportionately to the number of Hispanic infants. More importantly, the growth in the number of poor infants will occur disproportionately in places where Hispanics are concentrated-in new destinations and established gateways. ${ }^{10}$

For the first time in U.S. history, the U.S. Census Bureau reported that the majority of America's babies in 2011 were born to historically disadvantaged racial and ethnic minority women (that is, groups other than non-Hispanic whites). ${ }^{11}$ As we show here, the growth of the Hispanic population in new destinations, especially in rural areas, is spurred by high fertility, a situation that raises important questions about Hispanic integration and incipient patterns of economic and spatial inequality. For many Hispanic areas of new settlement, an older, largely nonpoor white population will increasingly be replaced over the foreseeable future by today's younger, disproportionately poor minority population. This racial and ethnic transformation will occur first and most rapidly in today's established and new Hispanic boomtowns, which are rapidly diversifying from the "bottom up."

Poor Hispanic infants face clear developmental disadvantages that threaten integration and America's future. In this report, we use the new fertility question in the 2006-2010 American Community Survey (ACS) to link the records of newborn infants to the poverty status of their mothers. We provide, for the first time, up-to-date national estimates of shares of children born into poverty. We have three specific objectiveseach framed conceptually by a model of spatial assimilation. First, we document ethno-racial variation in patterns of poverty among America's infants, distinguishing the disadvantaged circumstances of Hispanic infants from other ethno-racial groups. Second, we highlight "at risk" infants, focusing on variation in the incidence of poverty in new and established Hispanic destinations. We show that the geographical context of reception matters for Hispanics. Third, we highlight the demographic and sociocultural origins (i.e., risk factors) of high rates of poverty among Hispanic infants, including the parents' nativity status, family background, and human capital. 


\section{FIGURE 1. HISPANIC GROWTH PATTERNS, 1990 TO 2010}

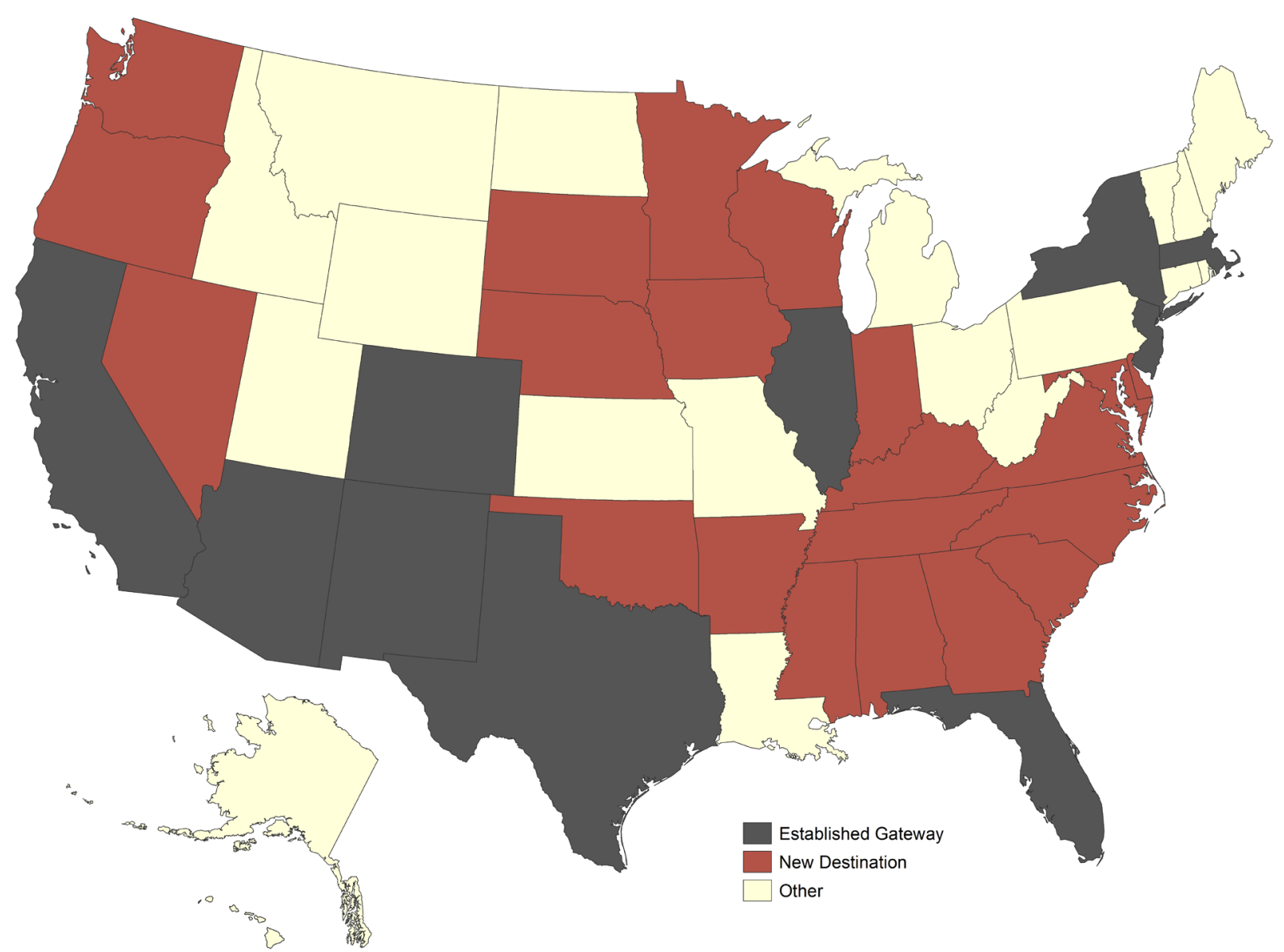

\section{High Fertility and Poverty Among Hispanics}

Hispanics represented 16 percent of the U.S. population in 2010 but accounted for 24 percent of all births. In part this is because Hispanic fertility is higher than fertility for the two major non-Hispanic groups. Overall, fertility rates are 20 percent higher for Hispanics than non-Hispanics (77.3 versus 64.2), and the differences are larger in nonmetro than in metro areas (Figure 2). High rates of Hispanic fertility in nonmetro areas are driven largely (but not entirely) by the high fertility of Mexican-origin Hispanics, who tend to be the least educated and skilled, and who typically have poverty rates well in excess of the native-born white population. ${ }^{12}$ Hispanic fertility rates are particularly high in the new destinations that are receiving significant net inflows of Hispanic migrants
(Figure 3). Such high Hispanic fertility rates coupled with the larger proportion of the Hispanic population in its childbearing years are giving demographic impetus to new diversity-from youngest to oldest. Under the circumstances, a careful look at poverty among Hispanic infants yields important new information about inequality and social integration, and an empirical basis for effective public policy.

Our estimates from the 2006-2010 ACS show that 23 percent of America's infants are born into poverty, but there are large racial and ethnic differences around this national average. Over one-third (34.9 percent) of all Hispanic infants today are born into poor families, a significant figure if considered in tandem with the large number of Hispanic births. Moreover, Hispanic poverty rates are exceptionally high among rural infants (Figure 4) and in new destinations (Figure 5). For Hispanics as for blacks, incorporation clearly is highly segmented geographically. 


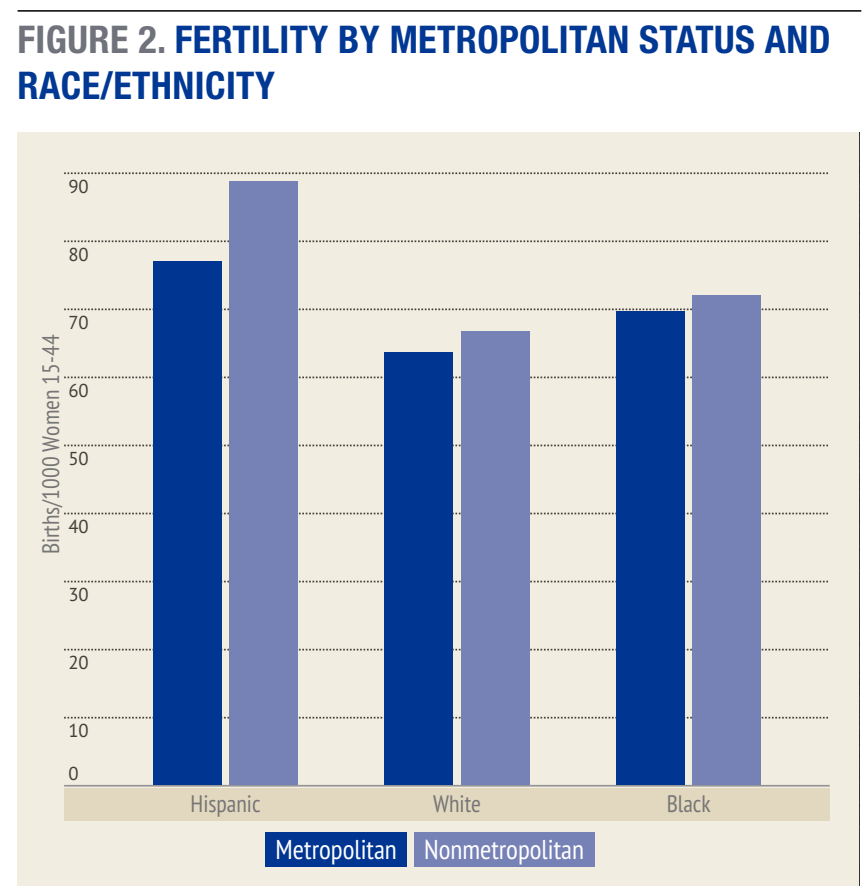

Source: U.S. Census 2006-2010 American Community Survey Microdata

\section{FIGURE 4. INFANTS IN POVERTY BY RACE/ETHNICITY AND METROPOLITAN STATUS}

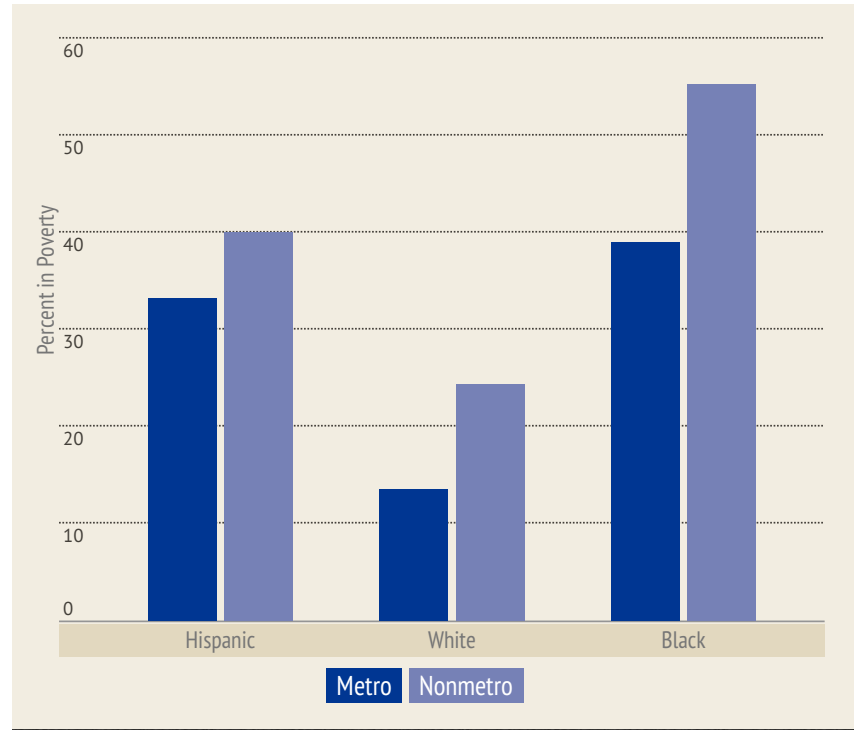

Source: U.S. Census 2006-2010 American Community Survey Microdata
FIGURE 3. FERTILITY BY DESTINATION TYPE AND RACE/ETHNICITY

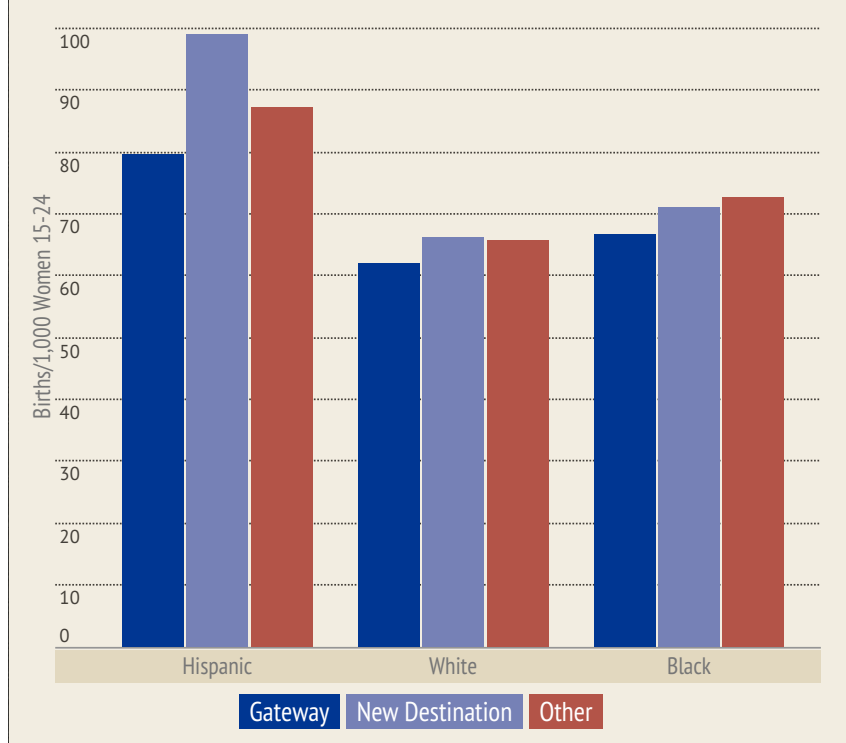

Source: U.S. Census 2006-2010 American Community Survey Microdata

\section{FIGURE 5. INFANTS IN POVERTY BY RACE/ETHNICITY AND DESTINATION TYPE}

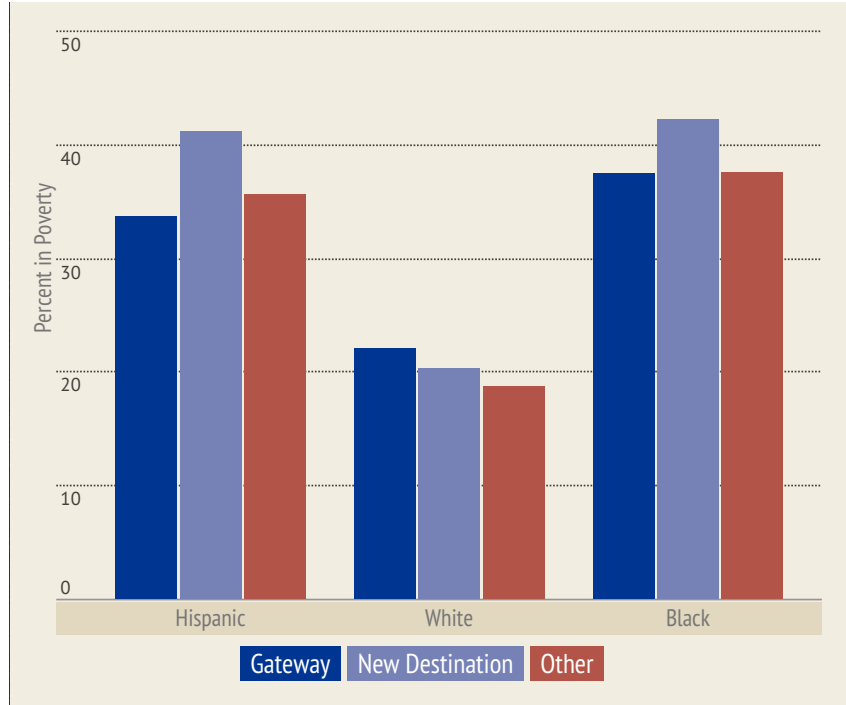

Source: U.S. Census 2006-2010 American Community Survey Microdata 


\section{Newborn Poverty Risks}

The likelihood that infants will be born into poverty depends on the situation of their mothers and the households into which they are born. Because maternal and household characteristics are experienced unequally across population subgroups, so too is the likelihood of being born poor. For example, an exceptionally large percentage -70 percent - of all Hispanic infants today are born to mothers with a high school degree or less, and the poverty rate among the infants of these mothers is 43 percent (Table 1 ). Though poverty is generally more likely for babies born to mothers with less education, far fewer Hispanic mothers are well educated. For example, only 12 percent of all Hispanic infants have college-educated mothers, compared to 32 percent of all infants. Such low educational levels among Latinas place their infants at greater risk of poverty.

The life course trajectories of infants are compromised as well by other maternal and household conditions that place them at risk. For example, about one in four Hispanic infants have mothers who began childbearing as teenagers, and nearly 46 percent of the infants born to these mothers were born poor. Though the likelihood of being born poor was high among all mothers who began childbearing as teens, Hispanics are more likely to begin having children as teens. Another risk factor for infant poverty among all mothers is out-of-wedlock childbearing. For Hispanics, nearly 54 percent of all infants born to single mothers are born into poverty. This figure is striking considering that roughly 40 percent of all Hispanic infants are born of single mothers.

Poverty risks are also higher among infants with foreign-born mothers and those with limited English. Hispanic infants are much more likely to have foreignborn mothers (52 percent), and those who do have a poverty rate of 38 percent. A disproportionately large share (12 percent) of Hispanic infants also have mothers who speak no English or poor English compared to all mothers (3 percent). Poverty rates are exceptionally high for Hispanic infants whose mothers have limited English (52.4 percent).

Poverty risks are significantly lower for Hispanic infants whose mothers are employed. Only 20 percent of Hispanic infants with working mothers are poor compared to 46 percent of those with unemployed mothers. However, just 42 percent of Hispanic mothers of infants work compared to 53 percent of all mothers of infants.

Though Hispanic infants face numerous risk factors, they are more likely to live in households with additional adult family members, a fact suggesting greater availability of secondary workers and potential adult caretakers. Indeed, over 24 percent of Hispanic infants were living in households with three or more related adults, compared with 19 percent of their non-Hispanic newborn counterparts. This "doubling up" provides a hedge against poverty for Hispanics, as reflected in the lower infant poverty rates in households with more workers.

The conventional view of spatial assimilation is that metro gateways provide an initial point of entry for Hispanic immigrant populations. Over time, upwardly mobile (and culturally assimilated) immigrants and their descendants then spread geographically to find new opportunities. Our results demonstrate that the majority of newborn Hispanics continue to reside in traditional gateways, but they are dispersing spatially to new destinations. Hispanic infants residing in such new destinations are at greater risk of poverty (39 percent) than their counterparts in traditional gateways (34 percent). The proportion of all Hispanic infants born in gateway states is still modest but it is growing, so the higher poverty rates among Hispanic infants there have significant implications both for Hispanics families and for the communities in which they reside.

\section{The overall risk of a Hispanic infant being born into poverty is nearly 2.8 times greater than the risk for a non-Hispanic white infant.}

We have shown that rural infant poverty rates are also higher than those for infants in metropolitan areas both among Hispanics and the population at large (see Figure 4). Hispanic infants born in rural new destinations are at a particularly high risk of poverty. ${ }^{13}$ The proportion of Hispanic infants born in rural areas remains modest, but the extra risk of poverty they face there is a cause for concern: in many rural counties Hispanic infants represent a disproportionate share of all births because the number of non-Hispanic births is dwindling.

The likelihood that an infant will be born into poverty is simultaneously influenced by the maternal, household, and geographic factors considered above. Using sophisticated statistical models, we combined these risk factors to estimate their joint impact on the likelihood of poverty for infants. ${ }^{14}$ These models suggest that the overall risk of a Hispanic infant being born into poverty is nearly 2.8 times greater than the risk for a non-Hispanic 
6 CARSEY SCHOOL OF PUBLIC POLICY

\section{TABLE 1. PARENTAL AND HOUSEHOLD CHARACTERISTICS OF NEWBORNS AND NEWBORNS IN POVERTY}

\section{ALL BIRTHS}

Percent of Newborns

\author{
Percent of Newborns Poor
}

HISPANIC BIRTHS

Percent of Newborns

Percent of Newborns Poor

\section{EDUCATION OF MOTHER}

High School or Less

Some College

College Graduate

AGE OF MOTHER

Less than 20

$20-24$

25 or more

MARITALSTATUS

$$
\text { Single }
$$

Married

NATIVITY OF MOTHER

Immigrant

Native Born

MOTHER AGE AT FIRST BIRTH

Teen First Birth

Adult First Birth

MOTHER ENGLISH ABILITY

$$
\text { No/Poor English }
$$

Good/Excellent English

EMPLOYMENT STATUS

Unemployed
Employed

47

53

3

97

6

20

74

32

68

24

76

17

83

ADULTS IN HOUSEHOLD

\begin{tabular}{c}
$1-2$ \\
$3-4$ \\
\hline 5 or more \\
GEOGRAPHY
\end{tabular}

81

11

8

46

31

23
19

52

22

35

13
33

31

4

47

38

17

50

11

26

22

44
70

18

12

10

24

67

40

60

48

26

74

12

88

58

42

24

16

22

25

24

21
76

16

8

76

16

8
46

20

43

21

9

47

40

30

54

22 
white infant. As we have seen, disparities in poverty are due, at least in part, to the overrepresentation of risk factors among Hispanic infants, particularly those born in rural areas. When infants with similar risk profiles are compared, the Hispanic disadvantage diminishes, but it is never fully eliminated. For example, in models that incorporate many of the risk factors discussed above, the predicted percent poor for Latino infants is 27.1 percent compared to 20.0 percent among whites, holding everything else in the model constant. That is, when Hispanic and non-Hispanic white infants living in similar circumstances with mothers with similar attributes are compared, differences in the likelihood of poverty diminish, but do not disappear.

In essence, much of the higher levels of poverty among Hispanic infants results from the disadvantages their mothers face. To put these poverty estimates in perspective, newborn Hispanic infants of unmarried, recent foreign-born immigrant teen mothers who speak little or no English are twenty-five times as likely to be born into poverty than are their Hispanic newborn counterparts whose mothers were married, were nativeborn, were age 20 or older, and spoke English well. The newborn children of low-educated, low-skilled Hispanic mothers face an exceptionally high risk of poverty, especially if the mother is unmarried. This is of particular concern given that 70 percent of Hispanic mothers have modest education and roughly 40 percent of the births in our sample were to unmarried women. ${ }^{15}$ Our models also suggest that infant poverty risks were significantly more likely among Hispanic infants who resided in rural new destinations compared to their counterparts in metro established gateways-suggesting that any deleterious effects associated with being born in a new Hispanic destination are largely limited to rural areas.

\section{A Coda on the Social Safety Net}

An important policy question is whether the families of newborn Hispanic infants are taking advantage of government support systems designed to diminish the adverse impacts of poverty on infants, or are they "falling through the cracks" in America's welfare safety net? Almost all Hispanic infants examined here were born in the United States, so they are citizens with the same rights and obligations as other native-born populations. Here we examine Hispanic infant utilization of government safety net programs (that is, cash assistance and supplemental nutrition assistance, or food stamps) and information on infants in families in deep poverty.
Only 12 percent of poor Hispanic infants reside in families accessing government cash assistance (Figure 6). This likely reflects the high shares of Hispanic infants with immigrant parents who may be unaware of or ineligible for government cash programs.

\section{FIGURE 6. ACCESS TO SAFETY NET BY POOR INFANTS AND INFANTS IN DEEPLY IMPROVERISHED FAMILIES}

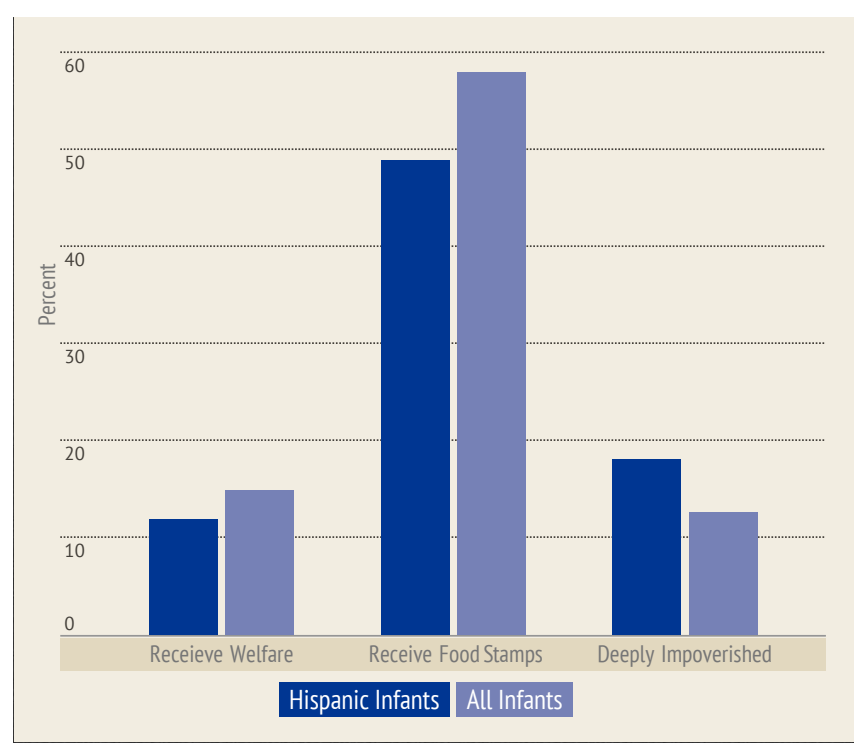

Source: U.S. Census 2006-2010 American Community Survey Microdata

About one-half of the families of poor Hispanic receive food stamps, though virtually all of these infants should be eligible to receive them. For both welfare and food stamps, the proportion of Hispanic infants receiving assistance is lower than the overall proportion of infants receiving assistance. This reflects high levels of unmet need among poor Hispanic families.

There is no evidence that Hispanic infants are ineligible for government benefits because they are only marginally poor. In fact, the average family income is only $\$ 11,194$ annually (over the 2006-2010 period) for poor Hispanic families with infants. For comparison, median U.S. family income in 2008 was almost six times greater-\$62,621. Many Hispanic infants are born into families that are deeply impoverished. Our calculations indicate that 18.1 percent of Hispanic infants are deeply impoverished (meaning income-to-poverty thresholds of less than 0.5 ) compared to 12.6 percent of all infants. 


\section{Discussion and Conclusion}

Hispanic population growth is now fueled mostly by births rather than by new immigrants. Our results show that poverty-like racial and ethnic diversitystarts from the "bottom up." Poverty in utero and at birth shapes a child's long-term cognitive development and the prospect of incorporation into American society. Early childhood poverty also tends to set into motion a series of lifecycle disadvantages (such as inadequate parenting, bad neighborhoods, underfunded schools, and poor health care) that greatly increases the likelihood of poverty in adulthood.

Our singular goal has been to shift the discussion to Hispanic fertility, while also providing empirical evidence of exceptionally high poverty among Hispanic infants, especially in rural areas. Poverty among recent Hispanic infants clearly raises the specter of new rural Hispanic ghettos and growing physical, social, and cultural isolation from the mainstream. ${ }^{16}$ The results suggest that the prospect of full incorporation into American society is jeopardized for many Hispanic infants. Indeed, our analysis reveals especially large disadvantages among rural Hispanic infants and those in new destinations. The substantive implication is that the lack of income from work and government (for example, cash assistance) in new destinations is experienced disproportionately by Hispanics. Hispanics have contributed to the revitalization of dying rural communities, but the payback, if measured in lower poverty rates, has been modest. ${ }^{17}$

\section{Policy makers may sometimes forget that the disadvantages faced by low-wage, low-skill immigrant Hispanic workers are often most keenly felt by their U.S.-born infants and chil- dren who, through no fault of their own, suffer the immediate and long-term consequences of low family income and concentrated poverty.}

Our findings suggest that a disproportionate share of newborn Hispanic infants start life well behind the starting line, living in fast-growing boom towns where they may never catch up. Unfortunately, the economic circumstances faced in new immigrant destinations-especially in rural areas-are too often ignored in metro-centric studies of immigrant adaptation and social integration. Although policy makers sometimes forget, the disadvantages faced by low-wage, low-skill immigrant Hispanic workers are often most keenly felt by their U.S.-born infants and children who, through no fault of their own, suffer the immediate and long-term consequences of low family income and concentrated poverty. For newborn children, trajectories of cognitive and emotional development and, ultimately, full economic incorporation into American society will be shaped by the families and communities in which they live. Whether today's Hispanic children will assimilate into America's economic mainstream is an open question that will take several generations to answer. But the Hispanic infants who will help reshape America's future require public policy attention now.

\section{Methods}

In our analysis we identify infants who were "born poor," that is, born to mothers who were below the poverty line in the infant's first year of life. Such information about infants has generally not been available in the past. However, the Census Bureau's American Community Survey (ACS) now makes it possible for the first time to identify infants born into impoverished families with a sample that is large enough to facilitate analysis of rural as well as urban areas and minority populations, including Hispanics. We use the 2006 through 2010 annual ACS microdata files to link infants (less than 1 year old) to data about their mothers and households in the year of their birth. Infants are identified as poor at birth if they lived in families with incomes below the official poverty income threshold.

Infants born to Hispanic mothers of any race are classified as Hispanic. All other infants are classified as non-Hispanic. In this brief, we focus on Hispanic, non-Hispanic white, and non-Hispanic black infants that together represent more than 90 percent of all births. Fertility rates reflect the number of births per 1,000 women 15 to 44 .

We consider a variety of demographic characteristics of the new mother that have been suggested as important in past research. We also consider factors commonly associated with maternal employment and human capital, including English-language ability (such as does the mother speak no or poor English), education, and employment status. 
The ACS microdata have limited geographic information, so we identify new destinations by state of residence, following the practice of other recent studies. Hispanic gateways or established destinations comprise ten states that, in 1990, accounted for roughly 90 percent of all U.S. Hispanics. ${ }^{18}$ These gateway states accounted for 76 percent of all recent Hispanic births. Since 1990, the geographic spread of the nation's Hispanics has accelerated; to reflect this, we define Hispanic new destinations as states that experienced a 250 percent or more increase in the size of their Hispanic population between 1990 and 2010. These twenty-one states reflect the movement of Hispanics to new areas including the Southeast, the Mississippi Delta, the agricultural heartland, and the Pacific Northwest. The residual category of twenty states (including the District of Columbia) represented in the "Other" category has slower Hispanic growth and comparatively small Hispanic populations (see Figure 1).

\section{End notes}

1. Kenneth M. Johnson and Daniel T. Lichter, "High Fertility, Low Mortality: Hispanic Natural Increase and the Growing Spatial Diversity of the U.S. Population," paper presented at the annual meeting of the Population Association of America, San Diego, CA, May 2015; Kenneth M. Johnson and Daniel T. Lichter, "Natural Increase: A New Source of Population Growth in Emerging Hispanic Destinations," Population and Development Review 34 (2008): 327-46.

2. Charles T. Clotfelter, Helen F. Ladd, and Jacob L. Vigdor, "New Destinations, New Trajectories? The Educational Progress of Hispanic Youth in North Carolina," Child Development 83 (2012): 1608-22; Greg J. Duncan, Kathleen M. Ziol-Guest, and Ariel Kalil, "Early-Childhood Poverty and Adult Attainment, Behavior, and Health," Child Development 81 (2010): 306-25.

3. Helen Marrow, "Assimilation in New Destinations," Daedalus 142 (2013): 107-22; Audrey Singer, The New Geography of United States Immigration (Washington, DC: Brookings Institution, 2009).

4. Kenneth M. Johnson and Daniel T. Lichter, "The Growing Diversity of America's Children and Youth: Spatial and Temporal Dimensions," Population and Development Review 36, no. 1 (2010): 151-76; Kenneth M. Johnson et al., "The Increasing Diversity of America's Youth: Children Lead the Way to a New Era," National Issue Brief No. 71 (Durham, NH: Carsey Institute, University of New Hampshire, 2014).

5. Eric I. Knudsen et al., "Economic, Neurobiological, and Behavioral Perspectives on Building America's Future Workforce," Proceedings of the National Academy of Sciences 103, no. 27 (2006): 10155-62; Jeanne Brooks-Gunn and Greg
J. Duncan, "The Effects of Poverty on Children," The Future of Children 7 (1997): 55-71; George J. Borjas, "Poverty and Program Participation Among Immigrant Children," The Future of Children 21 (2011): 247-66.

6. Leslie McCall and Christine Percheski, "Income Inequality: New Trends and Research Directions," Annual Review of Sociology 36 (2010): 329-47.

7. Frank D. Bean, C. Gray Swicegood, and Rachel Berg, "Mexican-Origin Fertility: New Patterns and Interpretations," Social Science Quarterly 81 (2000): 404-20; Emilio A. Parrado and S. Philip Morgan, "Intergenerational Fertility Among Hispanic Women: New Evidence of Immigrant Assimilation," Demography 45 (2008): 651-71; Gillian Stevens, "Social Mobility and Fertility: Two Effects in One," American Sociological Review 46 (1981): 573-85.

8. Marta Tienda and Faith Mitchell, eds., Hispanics and the Future of America (Washington, DC: National Academies Press, 2006).

9. Pia Orrenius and Madeline Zavodny, "Trends in Poverty and Inequality among Hispanics," in Robert S. Rycroft, ed., The Economics of Inequality, Poverty, and Discrimination in the 21st Century (Santa Barbara, CA: ABC-CLIO, 2013).

10. Daniel T. Lichter et al., "Hispanic Assimilation and Fertility in New U.S. Destinations," International Migration Review 46 (2012): 767-91.

11. Dennis Cauchon and Paul Overberg, "Census Data Shows Minorities Now a Majority of U.S. Births," USA Today, May 17, 2012, accessed on May 13, 2013 at http:// usatoday30.usatoday.com/news/nation/story/2012-05-17/ minority-births-census/55029100/1.

12. Daniel T. Lichter, Scott R. Sanders, and Kenneth M. Johnson, "Hispanics at the Starting Line: Poverty Among Newborn Infants in Established Gateways and New Destinations," Social Forces (2015, in press).

13. Ibid.

14. Ibid.

15. J.A. Martin et al., "Births: Final Data for 2012," National Vital Statistics Reports 62, no. 9 (2013).

16. Linda M. Burton, Raymond Garrett-Peters, and John Major Eason, "Morality, Identity, and Mental Health in Rural Ghettos," Social Disparities in Health and Health Care 1 (2011): 91-110.

17. Patrick J. Carr, Daniel T. Lichter, and Maria J. Kefalas, "Can Immigration Save Small-Town America? Hispanic Boomtowns and the Uneasy Path to Renewal," Annals of the American Academy of Political and Social Science 641 (2012): 38-57.

18. U.S. Census Bureau. 1993. Hispanic Population 1990. Accessed January 18, 2013 at www.census.gov/ prod/2001pubs/c2kbr01-3.pdf U.S. Census Bureau. 2012. 


\section{About the Authors}

Daniel T. Lichter is Ferris Family Professor in the Departments of Policy Analysis and Management and Sociology at Cornell University and a policy fellow at the Carsey School of Public Policy (dt128@cornell.edu).

Scott R. Sanders is an assistant professor in the Department of Sociology at Brigham Young University (scott_sanders@byu.edu).

Kenneth M. Johnson is senior demographer at the Carsey School of Public Policy and professor of sociology at the University of New Hampshire (ken.johnson@unh.edu).

\section{A cknow ledgments}

This brief is based on our article, "Hispanics at the Starting Line: Poverty Among Newborn Infants in Established Gateways and New Destinations," that appears in Social Forces in 2015, volume 94(1).

This research was supported by the Cornell Population Center and the Carsey School of Public Policy at the University of New Hampshire. The authors acknowledge the helpful advice of Marybeth Mattingly, Tim Heaton, and seminar participants at the WZB in Berlin in April 2013 and the Collegio Carlo Alberto in Turin, Italy. Dr. Lichter also benefitted from sabbatical support from the Netherlands Interdisciplinary Demographic Institute in Den Haag, The Netherlands. Dr. Johnson's work was supported by the W. K.

Kellogg Foundation, and production was supported by the W. K. Kellogg Foundation, the Annie E. Casey Foundation, and anonymous donors.

TH University of New Hampshire Carsey School of Public Policy

The Carsey School of Public Policy conducts policy research on vulnerable children, youth, and families and on sustainable community development. We give policy makers and practitioners timely, independent resources to effect change in their communities.

This work was supported by the Annie E. Casey Foundation, the W. K. Kellogg Foundation, and anonymous donors.

Huddleston Hall • 73 Main Street • Durham, NH 03824

(603) $862-2821$

TTY USERS: DIAL 7-1-1 OR 1-800-735-2964 (RELAY N.H.)

carsey.unh.edu 